\title{
Evaluating the Prospects of Ti-Base Lattice Infiltrated with Biodegradable Zn-2\%Fe Alloy as a Structural Material for Osseointegrated Implants-In Vitro Study
}

\author{
Noa Gabay*, Tomer Ron (D), Razi Vago, Amnon Shirizly (D) and Eli Aghion (D) \\ Department of Materials Engineering, Ben-Gurion University of the Negev, Beer Sheva 8410501, Israel; \\ toron@post.bgu.ac.il (T.R.); rvago@bgu.ac.il (R.V.); a.shirizly@gmail.com (A.S.); egyon@bgu.ac.il (E.A.) \\ * Correspondence: noagaba@post.bgu.ac.il
}

Citation: Gabay, N.; Ron, T.; Vago, R.; Shirizly, A.; Aghion, E. Evaluating the Prospects of Ti-Base Lattice Infiltrated with Biodegradable $\mathrm{Zn}-2 \% \mathrm{Fe}$ Alloy as a Structural Material for Osseointegrated Implants-In Vitro Study. Materials 2021, 14, 4682.

https://doi.org/10.3390/ma14164682

Academic Editor: Filippo Berto

Received: 19 July 2021

Accepted: 16 August 2021

Published: 19 August 2021

Publisher's Note: MDPI stays neutral with regard to jurisdictional claims in published maps and institutional affiliations.

Copyright: (c) 2021 by the authors. Licensee MDPI, Basel, Switzerland. This article is an open access article distributed under the terms and conditions of the Creative Commons Attribution (CC BY) license (https:// creativecommons.org/licenses/by/ $4.0 /)$.

\begin{abstract}
The term "osseointegrated implants" mainly relates to structural systems that contain open spaces, which enable osteoblasts and connecting tissue to migrate during natural bone growth. Consequently, the coherency and bonding strength between the implant and natural bone can be significantly increased, for example in operations related to dental and orthopedic applications. The present study aims to evaluate the prospects of a Ti-6Al-4V lattice, produced by selective laser melting (SLM) and infiltrated with biodegradable Zn2\%Fe alloy, as an OI-TiZn system implant in in vitro conditions. This combined material structure is designated by this study as an osseointegrated implant (OI-TiZn) system. The microstructure of the tested alloys was examined both optically and using scanning electron microscopy (SEM) and X-ray diffraction (XRD) analysis. The mechanical properties were assessed in terms of compression strength, as is commonly acceptable in cases of lattice-based structures. The corrosion performance was evaluated by immersion tests and electrochemical analysis in terms of potentiodynamic polarization and electrochemical impedance spectroscopy (EIS), all in simulated physiological environments in the form of phosphate buffered saline (PBS) solution. The cytotoxicity was evaluated in terms of indirect cell viability. The results obtained demonstrate the adequate performance of the OI-TiZn system as a non-cytotoxic structural material that can maintain its mechanical integrity under compression, while presenting acceptable corrosion rate degradation.
\end{abstract}

Keywords: osseointegration; additive manufacturing; SLM; lattice; Ti-6Al-4V; biodegradable Zinc; Zn-Fe; orthopedic; dental

\section{Introduction}

The initial definition of osseointegration claimed by Albrektsson et al. [1] was "a direct contact between a loaded implant surface and bone" that can practically improve the mechanical bonding between the permanent implant and the bone [2,3]. Currently, the novelty of producing implants through additive manufacturing (AM) technologies directly from a computer model enable the production of complex implants [4-7] that can be designated for a specific patient. In particular, this also relates to the capability of producing cellular material in the form of a structural lattice that inherently incorporates open space volume [8]. The structural lattice can then be infiltrated with a biodegradable alloy that slowly dissolves in in vivo conditions. In parallel, bone tissue can grow within the open space generated by the disintegration of the biodegradable alloy. Consequently, this can stimulate osseointegration processes in terms of improving the mechanical bonding between the natural bone and the permanent implant. A relatively similar type of approach was carried out by Balog et al. [9] by producing a composite system using an extruded mixture of $\mathrm{Ti}$ and $12 \%$ biodegradable $\mathrm{Mg}$ powder. They found that the degradation of $\mathrm{Mg}$ post-implantation could be replaced by bone tissue that enhances osseointegration. Another example of this type of approach was introduced by Jiang et al. [10]. They 
demonstrated that a $\mathrm{Ti}-\mathrm{Mg}$ system obtained by infiltrating pure biodegradable $\mathrm{Mg}$ into porous Ti matrix that was produced by applying controlled pressure on Ti wires within a cylindrical preform die.

The commonly preferred additive manufactured metal lattice for osseointegrated implants is Ti-6Al-4V alloy due to its outstanding mechanical properties and excellent biocompatibility [11-14]. Although Ti-6Al-4V alloy is widely used as a structural material for implants, sometimes it has the tendency to generate problems, such as stress shielding and cytotoxicity that is mainly attributed to the presence of vanadium. Hence, it should be pointed out that other Ti-base alloys are also being considered as of late, such as beta-type Ti-Nb-Zr-Mn alloys [15], Ti25Nb-13Ta-5Zr [16], and Ti-Al-Nb [17]. As for the infiltrated biodegradable metal, there are basically three common alternatives: Fe-base, $\mathrm{Mg}$ - base, and Zn-base alloys. Fe-based alloys tend to produce voluminous oxides that repel neighboring tissue, while Mg-based alloys suffer from accelerated corrosion rates that are associated with hydrogen gas evolution and an inherent risk of gas embolism [18-22]. In contrast, Zinc exhibited none of these disadvantageous characteristics [23-28]. In fact, Zn tends to stimulate bone growth [29] and act as an antibacterial material that is significantly effective in fighting infections [30-32]. However, research carried out by Guillory et al. [33] indicated that pure $\mathrm{Zn}$ may suffer from insufficient corrosion degradation rates in in vivo conditions that consequently can provoke fibrous encapsulation and limit the proper dissolution of the implant. To prevent this phenomenon, Fe and other alloying elements were added to pure Zinc in order to accelerate the corrosion rate by a micro-galvanic effect [34]. The present study aims to evaluate the prospects of a Ti-6Al-4V lattice infiltrated with biodegradable $\mathrm{Zn}-2 \% \mathrm{Fe}$ alloy as a structural material system for osseointegrated implants in in vitro conditions.

\section{Materials and Methods}

\subsection{Preparation of Osseointegrated Implants (OI-TiZn) System}

The OI-TiZn system was made from a permanent Ti-6Al-4V lattice produced by AM, which was subsequently infiltrated by a biodegradable $\mathrm{Zn}-2 \% \mathrm{Fe}$ alloy. The Ti- $6 \mathrm{Al}-4 \mathrm{~V}$ lattice was fabricated by an SLM process using an EOS-EOSINT M280 facility equipped with a $200 \mathrm{~W}$ Nd-YAG laser. The particle size of the Ti-6Al-4V powder was between $20-45 \mu \mathrm{m}$. The laser beam diameter was $60 \mu \mathrm{m}$, the scanning velocity was $7000 \mathrm{~mm} / \mathrm{s}$, the hatch spacing was $0.2 \mathrm{~mm}$, and the building layer thickness was $30 \mu \mathrm{m}$. The SLM scanning direction rotation was 45 degrees, and the lattice unit cell was in the form of a cubic structure with a $2.5 \mathrm{~mm}$ cell parameter and a rod diameter of $1 \mathrm{~mm}$. All the AM lattices were manufactured in the Z-direction and in accordance with ASTM standard 52921-13. The selection of $\mathrm{Zn}-2 \% \mathrm{Fe}$ as the biodegradable alloy mainly relates to the relative advantage of this alloy composition in terms of corrosion degradation $[18,34]$. This selection aims to avoid the danger of insufficient corrosion degradation rates, which can promote fibrous encapsulation and limit the dissolution of the infiltrated alloy [33]. The Zn-2\%Fe was produced by gravity casting using pure $\mathrm{Zn}$ ingots (99.99\%) and pure $\mathrm{Fe}(99 \%)$ powder with a mean grain size of 44 microns. The casting process of $\mathrm{Zn}-2 \% \mathrm{Fe}$ was carried out in a graphite crucible and included the following stages: (i) re-melting of pure $\mathrm{Zn}$ at $750^{\circ} \mathrm{C}$, and (ii) adding Fe powder with subsequent stirring every $30 \mathrm{~min}$ for $3 \mathrm{~h}$ [18]. Prior to the infiltration of the biodegradable $\mathrm{Zn}$ alloy, the Ti alloy lattice was pre-heated at $400{ }^{\circ} \mathrm{C}$ for $1 \mathrm{~h}$. The infiltration process was carried out by immersing the Ti alloy lattice in molten $\mathrm{Zn}$ alloy at a temperature above $700{ }^{\circ} \mathrm{C}$ within a steel die. In order to secure the proper filling of the Ti-base lattice, the infiltration process was accompanied by intensive shaking.

\subsection{Microstructure Examinations}

The microstructure of the tested materials was examined using JSM-5600 (Tokyo, Japan) scanning electron microscopy (SEM) integrated with an energy dispersive X-ray spectroscopy (EDS) detector (Thermo Fisher Scientific, Waltham, MA, USA) for localized chemical composition analysis with a spot size of $1 \mu \mathrm{m}$ [35]. Phase identification was 
carried out by X-ray diffraction (XRD) analysis, using an X-ray diffractometer (RIGAKU$2100 \mathrm{H}$ (Tokyo, Japan) with $\mathrm{Cu}-\mathrm{K} \alpha$. Diffraction patterns were generated in the range of $20^{\circ}-90^{\circ}$ at $40 \mathrm{kV}, 30 \mathrm{~mA}$, and a scanning rate of $0.02^{\circ} / \mathrm{min}$. The additively manufactured Ti6Al4V lattice and biodegradable $\mathrm{Zn}-2 \% \mathrm{Fe}$ alloy were separately tested as monolithic bulk materials. In order to examine the phases composing the interface between the Ti lattice and the biodegradable Zn-based alloy, the OI-TiZn system was tested in the form of powder subsequent to the removal of intact Ti-base lattice rods. Prior to the XRD analysis, the final powder was ground to obtain a fine grain size of about $100 \mu \mathrm{m}$.

\subsection{Compression Strength}

The mechanical properties of the Ti-lattice and the OI-TiZn system were evaluated in terms of compressive strength, as is commonly acceptable in analyzing three dimensional lattices $[10,36]$. This was carried out using a Hounsfield H25 KT testing facility with a crosshead-speed of $0.5 \mathrm{~mm} / \mathrm{min}$. The test specimens had a cylindrical shape with dimensions of a $10 \mathrm{~mm}$ diameter and a $20 \mathrm{~mm}$ length, and were obtained by an electroerosion cutting machine (ARTA 123Pro EDM).

\subsection{Immersion Test}

The corrosion resistance of the OI-TiZn system and of the biodegradable $\mathrm{Zn}-2 \% \mathrm{Fe}$ alloy in equilibrium conditions were examined in terms of immersion tests for 14 days. The testing solution was phosphate buffered saline (PBS) and the temperature was $37^{\circ} \mathrm{C}$, respectively, to simulate typical physiological environmental conditions in accordance with the ASTM ID: G31-72 standard. The specimens for the immersion tests were in the form of cylindrical rods with a $10 \mathrm{~mm}$ diameter and an $8 \mathrm{~mm}$ length. The specimens were produced by an ARTA 123Pro EDM electro-erosion cutting machine.

The corrosion rate was calculated according to the following equation:

$$
C R=\frac{W}{A \cdot T \cdot D}
$$

where $W$ is the weight loss, $A$ is the exposed area, $T$ is the duration time, and $D$ is the density of the specimen.

\subsection{Electrochemical Behavior}

The electrochemical behavior of the tested materials was evaluated using a Bio-Logic SP-200 potentiostat equipped with EC-Lab software V11.18. This was also carried out in the PBS solution using a three-electrode cell that included a working electrode with an exposed area of $1 \mathrm{~cm}^{2}$, a saturated calomel electrode (SCE) as a reference electrode, and a platinum counter electrode. The scanning rate of potentiodynamic polarization analysis was $1 \mathrm{mV} / \mathrm{s}$. The electrochemical impedance spectroscopy (EIS) analysis was carried out within the range of $10 \mathrm{kHz}-100 \mathrm{MHz}$ at $10 \mathrm{mV}$ amplitude. Prior to all electrochemical analysis, the samples were polished to 1200 grit. The corrosion rate was evaluated by Tafel extrapolation [37].

\subsection{Cytotoxicity Testing}

Cytotoxicity testing was carried out by evaluating the effect of indirect extract on cell metabolic activity according to the ISO 10993-5/12 standard. The cytotoxicity analysis was conducted using Mus musculus (mouse) 4T1 cells, due to their relatively increased sensitivity to toxic effects. In fact, those cells are significantly more active than primary cells, and consequently more sensitive to toxic conditions. Prior to the cytotoxicity tests, Ti-6Al$4 \mathrm{~V}$ samples produced by an SLM process and OI-TiZn samples-both having a diameter of $7.9 \mathrm{~mm}$ and a length of $2 \mathrm{~mm}$ - underwent the following treatments: (i) polished up to 4000 grit, (ii) cleaned in ethanol for $10 \mathrm{~min}$, (iii) cleaned in acetone for $5 \mathrm{~min}$, and (iv) sterilized in UV light for $1 \mathrm{~h}$ on each side. The required extract was obtained by immersing the related specimens in Dulbecco Modified Eagle's Medium (DMEM) solution with $4.5 \mathrm{~g} / \mathrm{L}$ 
D-Glucose, 10\% Fetal Bovine Serum (FBS), $4 \mathrm{mM}$ L-Glutamine, $1 \mathrm{mM}$ Sodium Pyruvate (SP), and $1 \%$ Penicillin Streptomycin Neomycin (PSN) antibiotic mixture under a $5 \% \mathrm{CO}_{2}$ humidified atmosphere for $24 \mathrm{~h}$ at $37^{\circ} \mathrm{C}$. The surface area to volume extraction ratio was $1.25 \mathrm{~cm}^{2} / \mathrm{mL}$. The extracts were then collected and filtered using a PVDF membrane of $0.45 \mu \mathrm{m}$. The $4 \mathrm{~T} 1$ cells were seeded in 96-well tissue culture plates, in a concentration of 5000 cells per well, and incubated for $24 \mathrm{~h}$ to allow for proper rehabilitation. The cells' medium was then replaced by $100 \mu \mathrm{L}$ of the following extracts (4 wells of each group): Ti-6Al-4V as the control group, and OI-TiZn extracts, diluted to 1:10 (10\%) to correspond to the biological ability to naturally dilute and rid excesses of $\mathrm{Zn}[38,39]$. As additional positive and negative control groups, 4 wells' mediums were replaced with $100 \mu \mathrm{L}$ of only DMEM, and 4 wells' mediums were replaced with $100 \mu \mathrm{L}$ of $90 \%$ DMEM and 10\% DMSO, respectively. Two identical 96-well plates were incubated for $24 \mathrm{~h}$ and $48 \mathrm{~h}$. The cell viability was assessed using a Cell Proliferation Kit (XTT, Biological Industry, Beit Haemek, Israel). According to this process, each sample (in addition to 3 blank wells as reference) was incubated for $2 \mathrm{~h}$ in $100 \mu \mathrm{L}$ DMEM, $50 \mu \mathrm{L}$ reagent, and $1 \mu \mathrm{L}$ activator. The color transformation was measured spectrophotometrically at $490 \mathrm{~nm}$ using a microplate reader (SYNERGY-Mx, BioTek, Winooski, VT, USA). The obtained values were compared with the control blank samples in order to assess the cell viability. The general appearance of each sample was visually examined using a CoolLED pE-2 collimator fitted to an inverted phase-contrast microscope (Eclipse Ti, Nikon, Tokyo, Japan) equipped with a digital camera (DS-Qi1Mc, Nikon, Tokyo, Japan). The tests were repeated twice independently to validate the obtained results.

\section{Results}

\subsection{Preparation of OI-TiZn Samples and Microstructure Examinations}

The general appearance of the Ti-6Al-4V lattice obtained by the SLM process is shown in Figure 1a. This illustrates the symmetric cubic structure of the lattice, as well as the locations of open spaces marked by the darker areas. A close-up view of the Ti-base lattice infiltrated with biodegradable $\mathrm{Zn}-2 \% \mathrm{Fe}$ alloy is shown in Figure $1 \mathrm{~b}$. This clearly reveals that the infiltrated alloy was able to both penetrate and fill the open spaces within the lattice with good matching to the internal titanium structure.
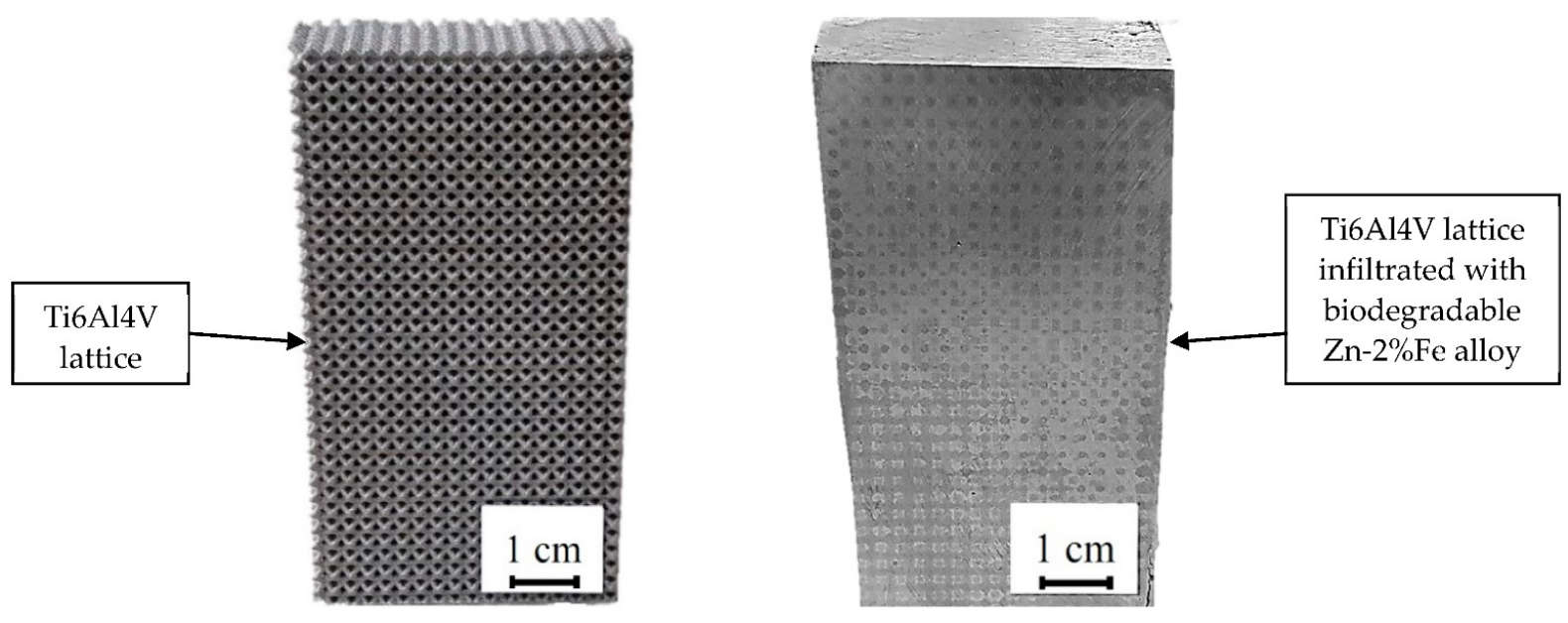

(a)

Figure 1. Cont. 

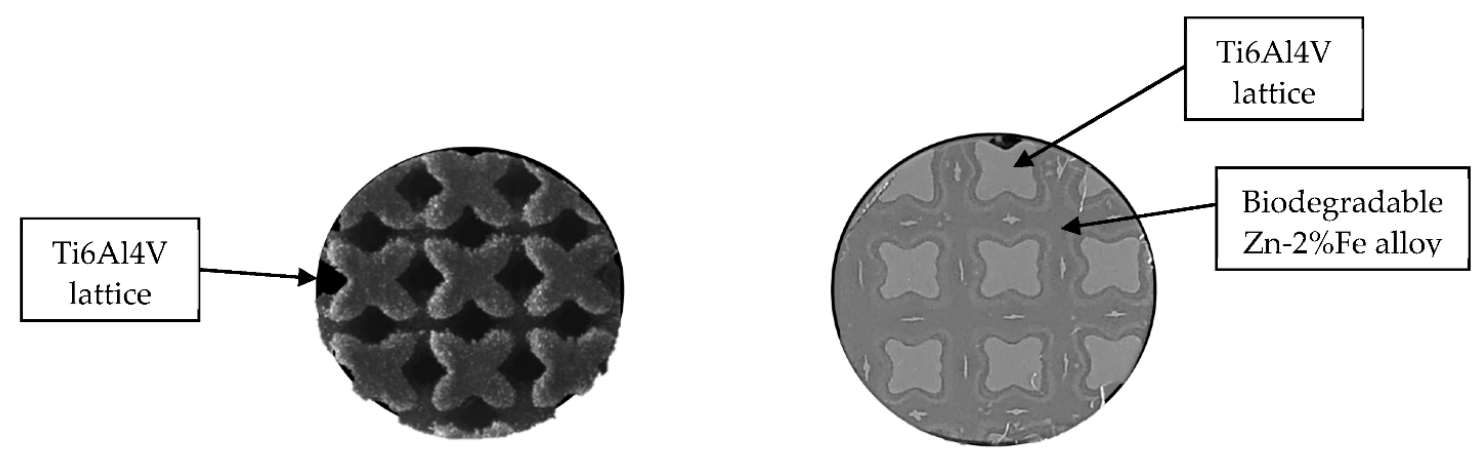

(b)

Figure 1. (a,b) General and close-up views of Ti-base lattice and infiltrated lattice (OI-TiZn system), respectively.

A close-up view of the boundary between the Ti-base lattice and the infiltrated $\mathrm{Zn}$ $2 \%$ Fe alloy, as obtained by SEM back scatter electron (BSE) analysis, is shown in Figure 2a. A magnified view of that boundary clearly discloses the presence of an interface layer with a width of about $130 \mu \mathrm{m}$ attached to the Ti-base rods, as shown in Figure 2b.

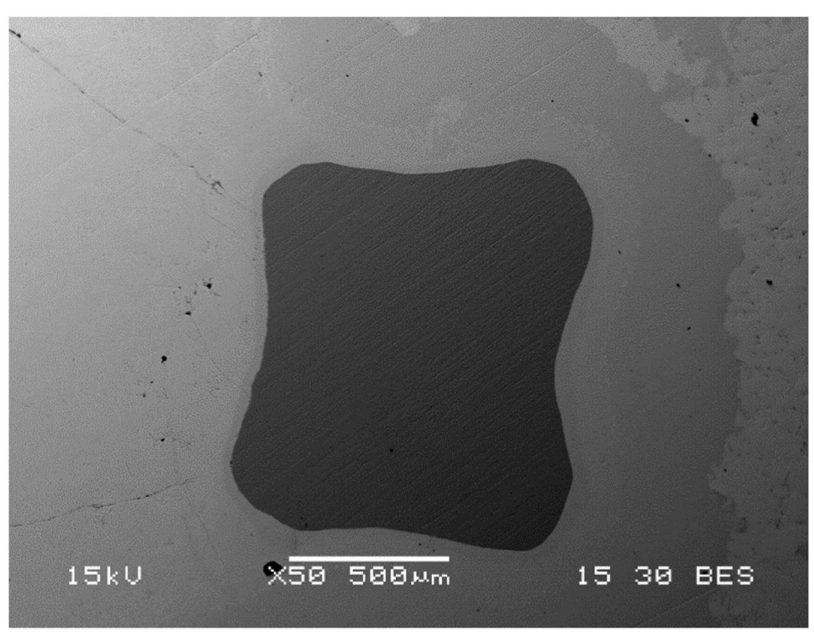

(a)

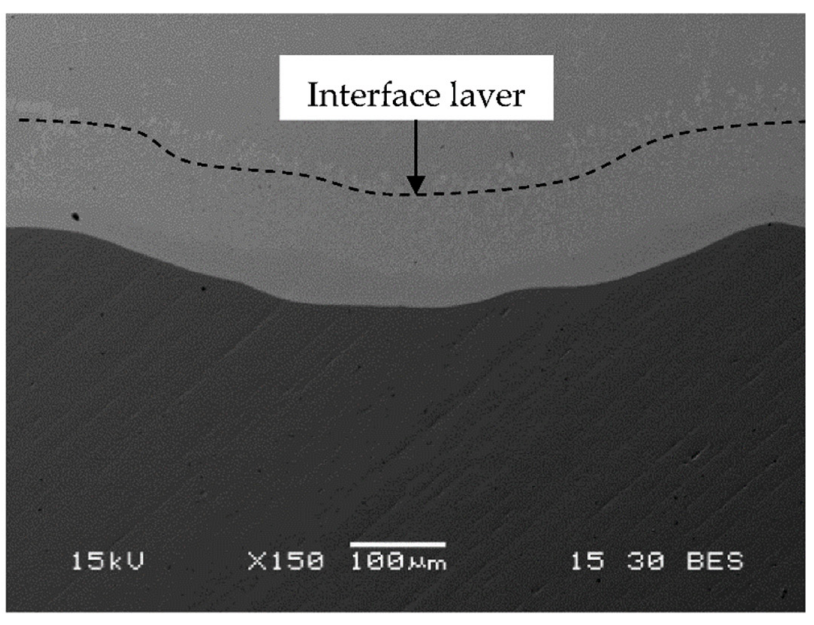

(b)

Figure 2. General appearance of the boundary between the Ti-6Al-4V lattice and the infiltrated $\mathrm{Zn}-2 \%$ Fe alloy: (a) close-up view and (b) magnified view of the interface layer between the two alloys. 
In order to evaluate the characteristics of the interface layer between the Ti-base lattice rods and the infiltrated $\mathrm{Zn}-2 \%$ Fe alloy, the chemical composition of this layer was analyzed by energy-dispersive spectroscopy (EDS), as shown in Figure 3. This has indicated that a relatively large amount of $\mathrm{Ti}$ was present in this layer, along with a large amount of $\mathrm{Zn}$. According to the spot chemical analysis shown in Figure 4 (points 2 and 3), the amount of $\mathrm{Ti}$ in this layer was within the range of $20.2-23.4 \%$, along with $0.5-1.7 \%$ Fe. In parallel, the content of other alloying elements composing the Ti-base lattice ( $\mathrm{Al}$ and $\mathrm{V}$ ) within this layer were relatively minor compared to their original content in the $\mathrm{Ti}-6 \mathrm{Al}-4 \mathrm{~V}$ alloy.

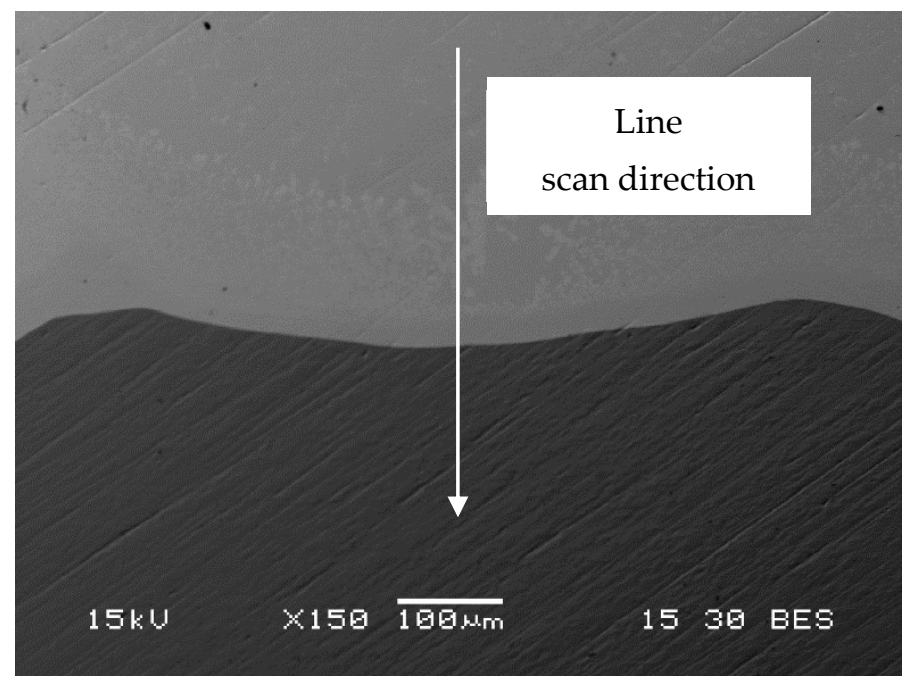

(a)

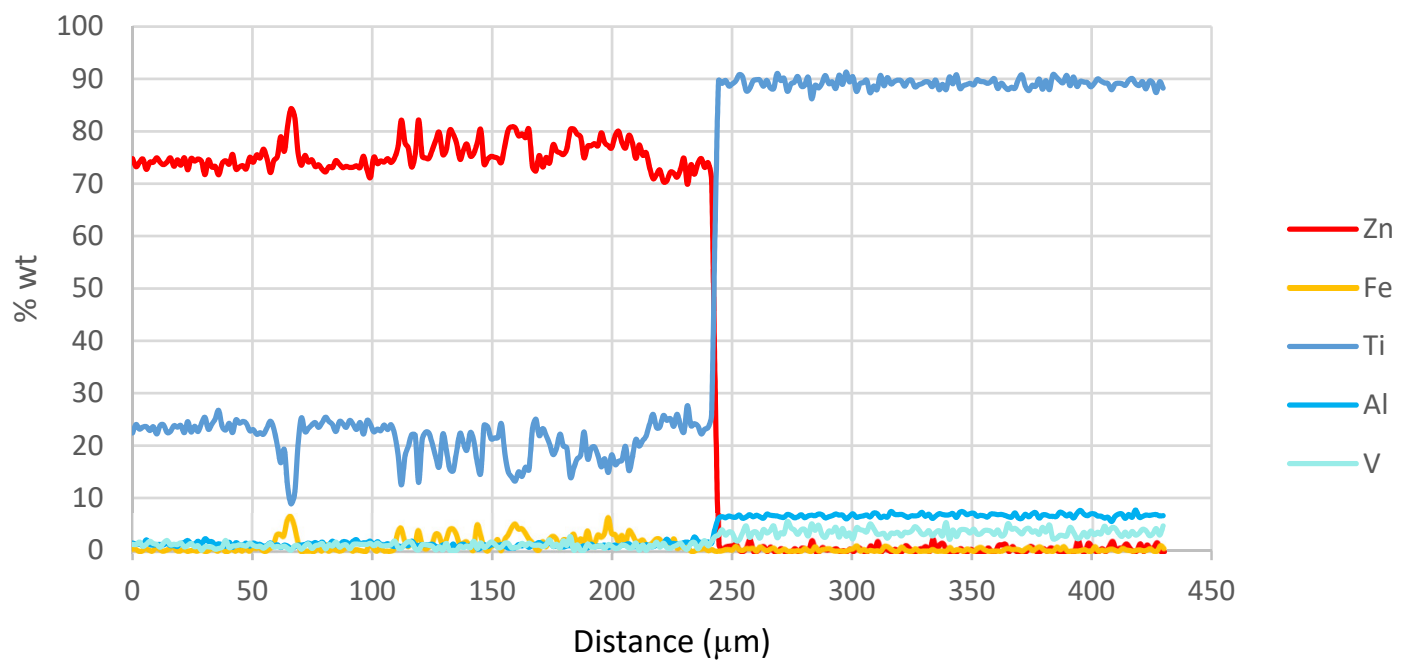

(b)

Figure 3. Chemical composition of the interface layer between the Ti-base lattice and infiltrated Zn-2\%Fe alloy-(a) line scan direction and (b) chemical composition obtained by EDS analysis. 


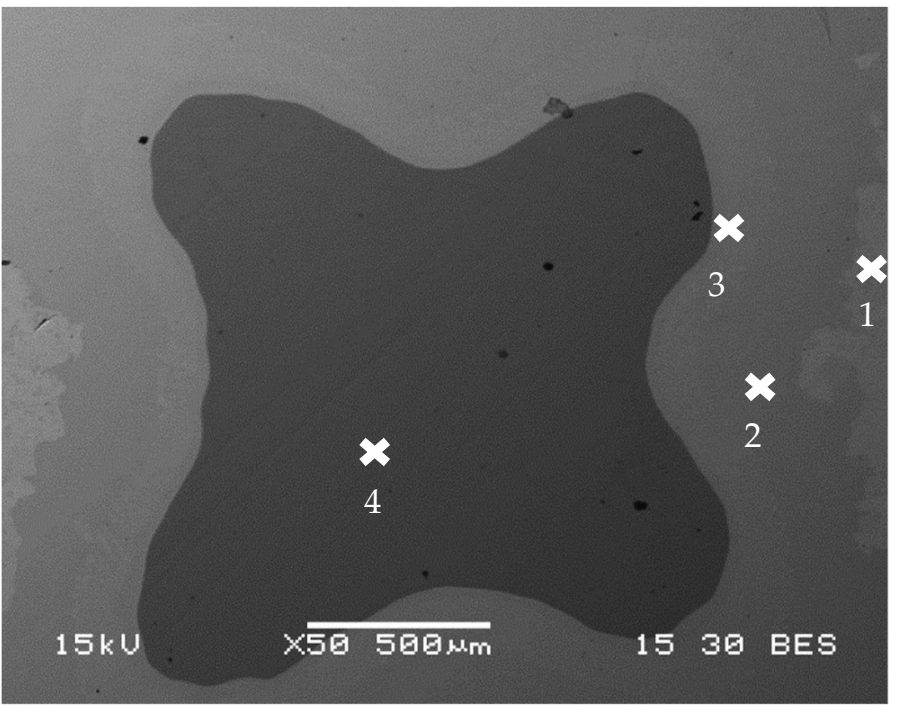

\begin{tabular}{cccccc}
\cline { 2 - 6 } Point of measurement & \multicolumn{5}{c}{ Element content (\%at) } \\
\cline { 2 - 6 } & $\mathrm{Zn}$ & $\mathrm{Fe}$ & $\mathrm{Ti}$ & $\mathrm{Al}$ & $\mathrm{V}$ \\
\hline 1 & 87.0 & 8.3 & 4.3 & 0.4 & 0.0 \\
\hline 2 & 73.8 & 0.5 & 23.4 & 1.3 & 1.0 \\
\hline 3 & 75.9 & 1.7 & 20.2 & 1.3 & 0.9 \\
\hline 4 & 0.4 & 0.0 & 89.0 & 6.8 & 3.8 \\
\hline
\end{tabular}

Figure 4. Spot chemical composition measurements along the border obtained by EDS analysis with an error of $2 \%$ at.

Further investigation of the interface layer was carried out by an XRD analysis. Figure 5 a reveals the phase characteristics of the Ti-base lattice that was mainly composed of martensitic phase $\left(\alpha^{\prime}\right)$ due to rapid solidification conditions, as expected from Ti-6Al-4V alloy produced by an SLM process. The XRD analysis of the biodegradable $\mathrm{Zn}-2 \% \mathrm{Fe}$ alloy indicated the presence of pure $\mathrm{Zn}$ matrix and a secondary phase in the form of $\mathrm{Zn}_{11} \mathrm{Fe}$, as shown in Figure $5 \mathrm{~b}$. The diffraction analysis of a mixed powder of the OI-TiZn system without the intact Ti-base lattice rods is shown in Figure 5c. This reveals the presence of pure $\mathrm{Zn}$, along with a dominant secondary phase in the form of $\mathrm{TiZn}_{3}$. According to the ternary phase diagram $(\mathrm{Fe}-\mathrm{Ti}-\mathrm{Zn})$ presented by Raghavan [40], the $\mathrm{TiZn}_{3}$ phase can be obtained in concentrations of over $95 \%$ wt $\mathrm{Zn}, 10-25 \%$ wt Ti, and $0-3 \%$ Fe. This comes in line with the spot chemical composition analysis at the interface layer, as shown in Figure 4, where the Ti content was $15.8-18.4 \%$ wt and the Fe content was $0.47-1.58 \%$. 


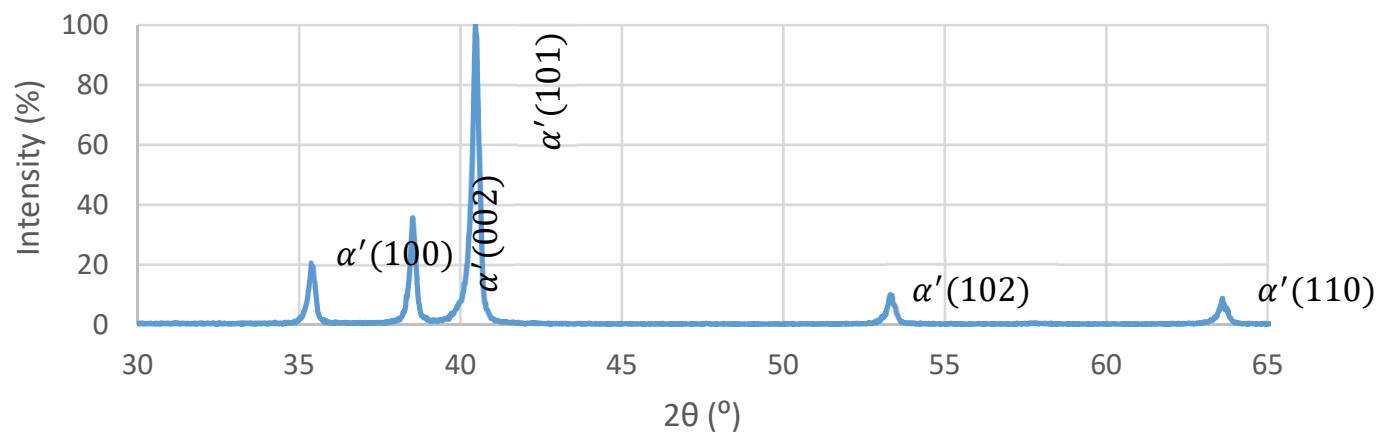

(a)

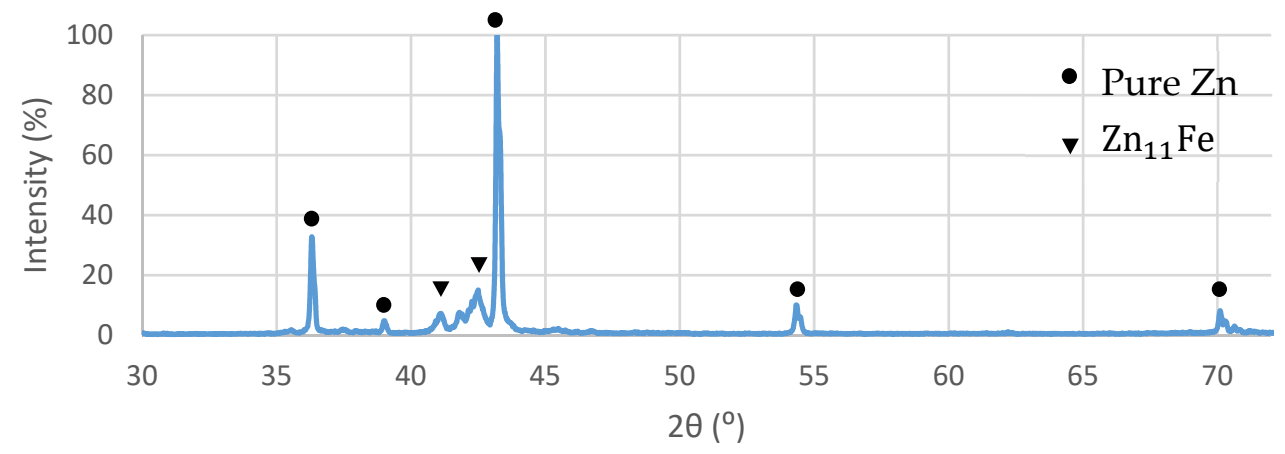

(b)

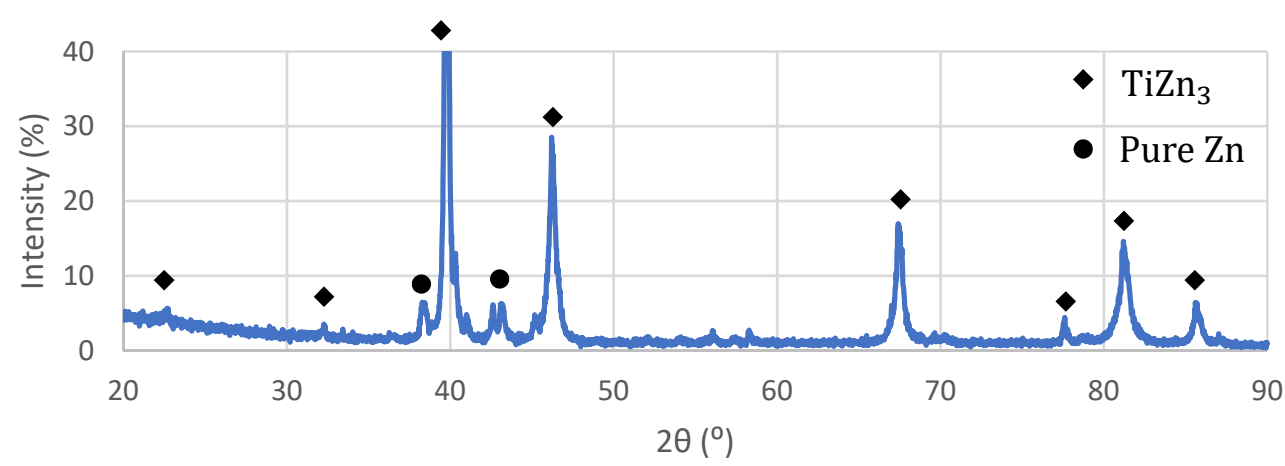

(c)

Figure 5. XRD analysis of (a) Ti-6Al-4V lattice, (b) Zn-2\%Fe alloy, and (c) mixed powder of OI-TiZn system without the intact Ti-base lattice rods.

\subsection{Mechanical Properties in Terms of Compression Strength}

The mechanical properties of the Ti-base lattice and the OI-TiZn system along the $\mathrm{XZ}$ plane were evaluated in terms of compression tests. Typical stress-strain curves are shown in Figure 6, along with the statistical deviations of the mechanical properties as presented in Table 1. The nominal cross section area of the lattice was calculated using the following equation:

$$
A_{L}=V_{L} / h_{L}
$$


where $A_{L}$ is the cross-section area of the lattice, $h_{L}$ is the height of the sample, and $V_{L}$ is the cylindrical volume of the specimen obtained by the following relation:

$$
V_{L}=W_{L} / \rho
$$

where $W_{L}$ is the weight of the specimen, and $\rho$ is the density, taken as $4.4 \mathrm{~g} / \mathrm{cm}^{3}$ [41].

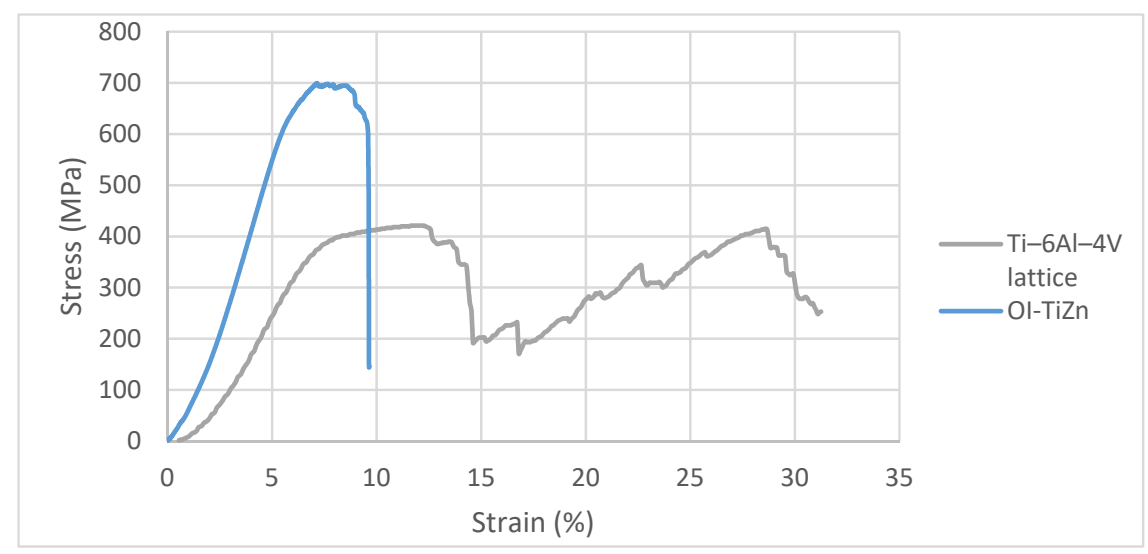

Figure 6. Typical compressive stress-strain curves of Ti-6Al-4V lattice and OI-TiZn system.

The obtained results showed a repeated loss and recovery of strength by the Ti-alloy lattice that can be related to the collapsing of cells along XZ planes, as indicated by Maskery et al. [42]. In comparison, the stable strength performance of the OI-TiZn system with a naturally higher ultimate compressive strength (UCS) and yield strength compared to the Ti-base lattice is in line with the basic observations of Jiang et al. [10]. The failure mode of the Ti-base lattice shown in Figure 7a displays a layer-by-layer crushing due to shear deformation. Contrarily, the mode of failure of the OI-TiZn system (Figure 7b) was dominated by the infiltrated $\mathrm{Zn}-2 \% \mathrm{Fe}$ alloy and resulted in pure shear fracture, while maintaining the important mechanical integrity of the OI-TiZn system. According to Jiang et al. [36], this type of fracture can be related to the critical resolved shear stress developed along the internal planes of the OI-TiZn system.
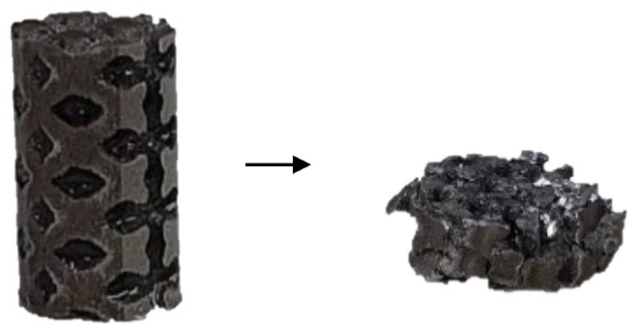

(a)
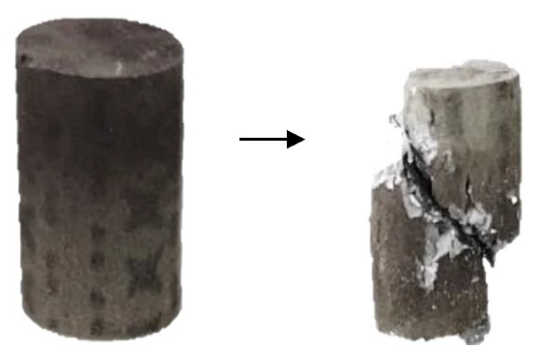

(b)

Figure 7. Typical mode of failure obtained under compression stress of (a) Ti-6Al-4V lattice, (b) OITiZn system. 
Table 1. Statistical deviations of the mechanical properties under compressive loading of Ti-base lattice and OI-TiZn system.

\begin{tabular}{ccc}
\hline & Ultimate Compressive Strength (UCS) (MPa) & Yield Point (MPa) \\
\hline Ti-6Al-4V lattice & $429.9 \pm 6.3$ & $397.9 \pm 2.6$ \\
OI-TiZn system & $699 \pm 120$ & $606 \pm 53$ \\
\hline
\end{tabular}

\subsection{Corrosion Resistance and Electrochemical Behavior}

The corrosion performance of the biodegradable $\mathrm{Zn}-2 \% \mathrm{Fe}$ alloy and the OI-TiZn system under an immersion test in the PBS solution at $37{ }^{\circ} \mathrm{C}$ for 14 days is shown in Figure 8. This reveals that the corrosion rate of the OI-TiZn system was significantly higher, apparently due to the galvanic effect created between the Ti-base lattice and the infiltrated $\mathrm{Zn}-2 \% \mathrm{Fe}$ alloy. This assumption was clearly supported by the general corrosion attack views shown in Figure 9, which demonstrate the increased corrosion attack at the boundary between the Ti-base rods and infiltrated alloy. A magnified view of this galvanic corrosion is shown in Figure 10. This noticeably reveals the significant degradation of the infiltrated $\mathrm{Zn}-2 \% \mathrm{Fe}$ alloy, and the vicinity of the Ti-base lattice that was kept nearly intact in parallel.

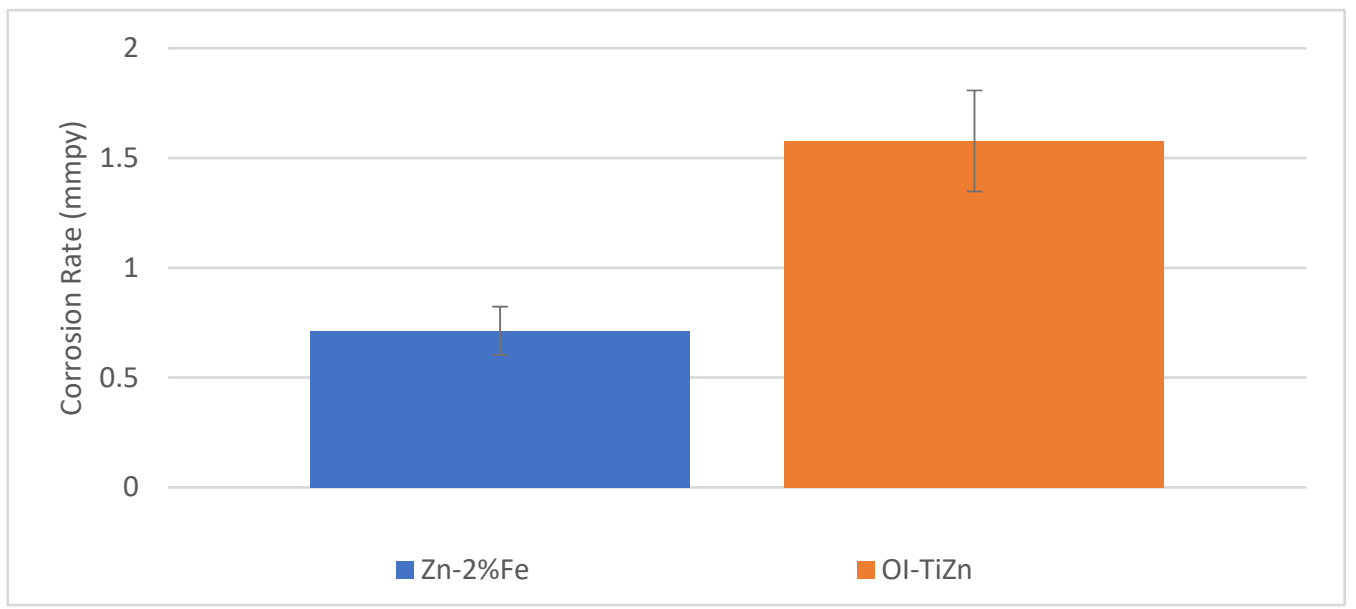

Figure 8. Corrosion rate measurements obtained after immersion tests of $\mathrm{Zn}-2 \% \mathrm{Fe}$ alloy and OI-TiZn system in PBS solution at $37^{\circ} \mathrm{C}$ for 14 days.

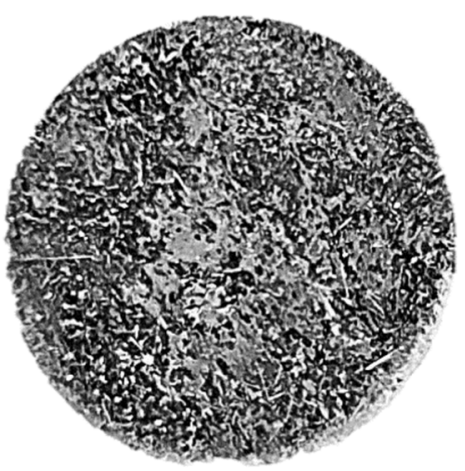

(a)

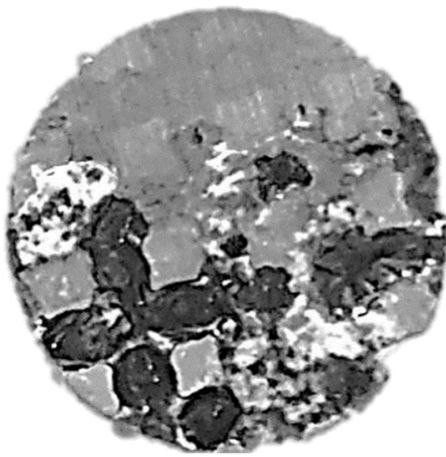

(b)

Figure 9. General appearance of corrosion attack obtained after 14 days of immersion test: (a) Zn$2 \%$ Fe alloy and (b) OI-TiZn system. 


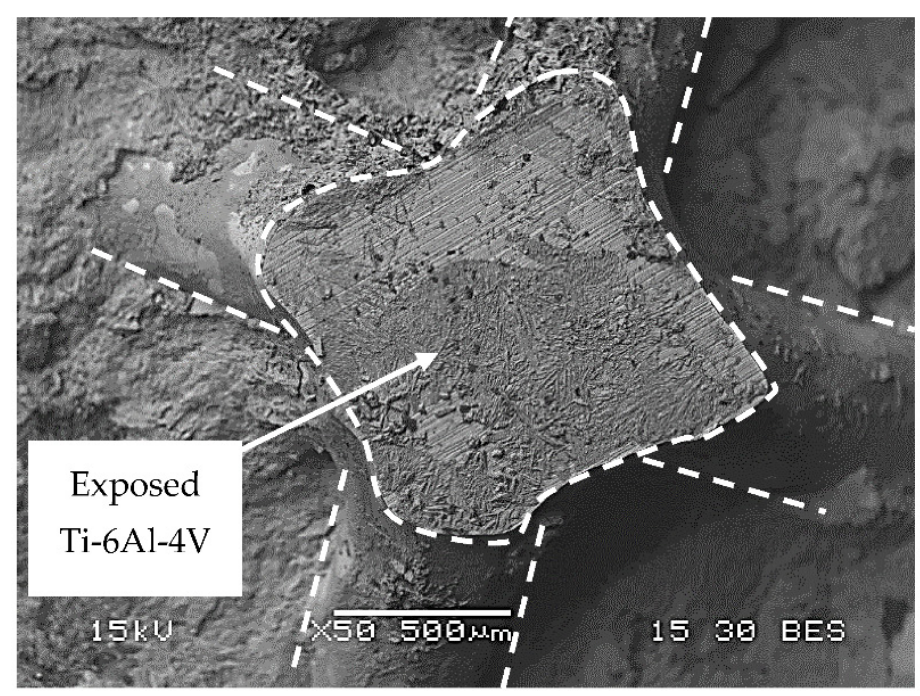

Figure 10. A magnified view of the galvanic corrosion attack in the vicinity of the Ti-base lattice after immersion test for 14 days.

An electrochemical analysis in terms of potentiodynamic polarization of Ti-6Al$4 \mathrm{~V}$ alloy, biodegradable $\mathrm{Zn}-2 \% \mathrm{Fe}$ alloy, and the OI-TiZn system is shown in Figure 11. This indicates that the polarization curve of the OI-TiZn system was shifted to higher current densities, indicating an increased corrosion rate [43]. This was supported by Tafel extrapolation (Table 2), which clearly revealed that the corrosion rate of the OI-TiZn system was higher by about three orders of magnitude as compared to the Ti-base lattice, and by less than two orders of magnitude as compared to the biodegradable $\mathrm{Zn}-2 \% \mathrm{Fe}$ alloy. This electrochemical outcome clearly demonstrates the dominant effect of the infiltrated $\mathrm{Zn}-2 \% \mathrm{Fe}$ alloy on corrosion tendencies of the OI-TiZn system. In addition, these results comply with the results obtained by the immersion tests, and the assumptions related to the substantial effects of galvanic corrosion.

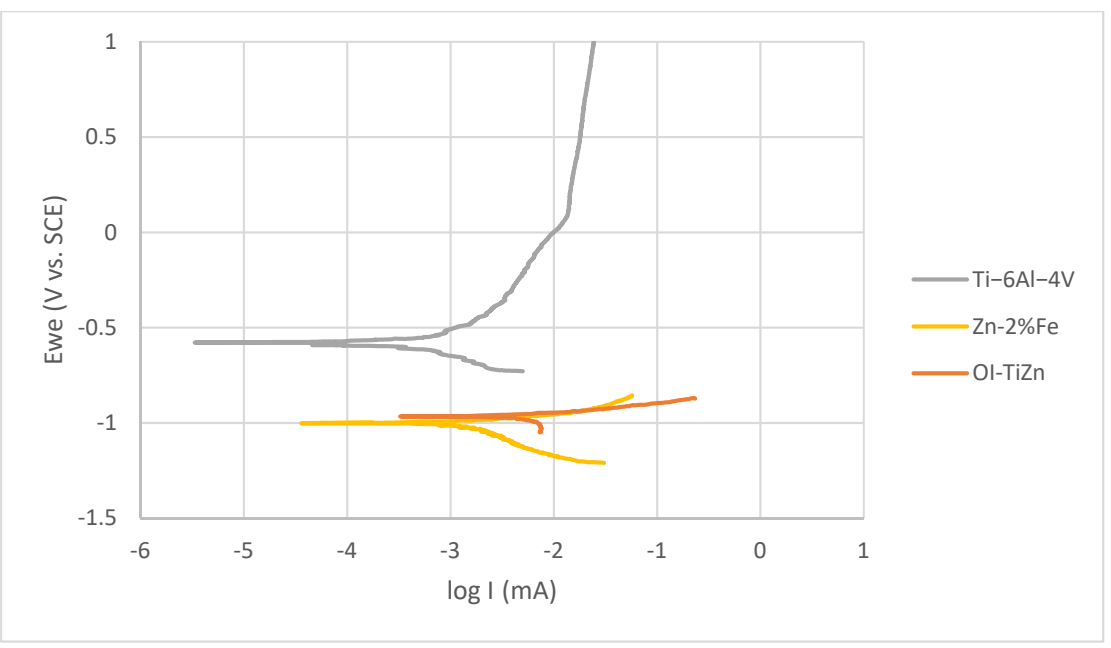

Figure 11. Potentiodynamic polarization analysis of Ti-6Al-4V lattice, Zn-2\%Fe alloy, and OI-TiZn system in PBS solution.

Table 2. The results obtained by Tafel extrapolation including statistical deviations.

\begin{tabular}{cccc}
\hline & Ti-6Al-4V & Zn-2\%Fe & OI-TiZn \\
\hline $\mathrm{E}_{\text {corr }}(\overline{\mathrm{V}})$ vs. SCE & $-0.52 \pm 0.06$ & $-1.03 \pm 0.05$ & $-0.965 \pm 0.001$ \\
$\mathrm{I}_{\text {corr }}(\mu \mathrm{A})$ & $0.80 \pm 0.27$ & $2.22 \pm 2.05$ & $9.95 \pm 0.26$ \\
Corrosion Rate $(\mathrm{mmpy})$ & $0.005 \pm 0.002$ & $0.033 \pm 0.031$ & $0.149 \pm 0.004$ \\
\hline
\end{tabular}


A further investigation of the electrochemical behavior of the tested materials was carried out using EIS in terms of a Nyquist plot, as shown in Figure 12a. This clearly shows a significant reduction in the radii of curvature of the OI-TiZn system as compared to both Ti-base lattice and $\mathrm{Zn}-2 \% \mathrm{Fe}$ alloy. According to Kafri et al. [18], the reduced radius of curvature is an indication of a reduced corrosion resistance. The electrical equivalent circuit fitted to the Nyquist plots is shown in Figure 12b, where R1 represents the solution resistance, R2 the specimen's resistance, and Q2 the capacitor created by the double layer. The values derived from the plots in correlation with the electrical circuit are shown in Table 3. This indicates that the resistance R2 of the OI-TiZn system was reduced by one order of magnitude, as compared to that of the Ti-base lattice alloy and the $\mathrm{Zn}-2 \% \mathrm{Fe}$ alloy. Altogether, the results of the EIS are in accord with the outcome obtained by the potentiodynamic polarization analysis and the immersion test.

(a)

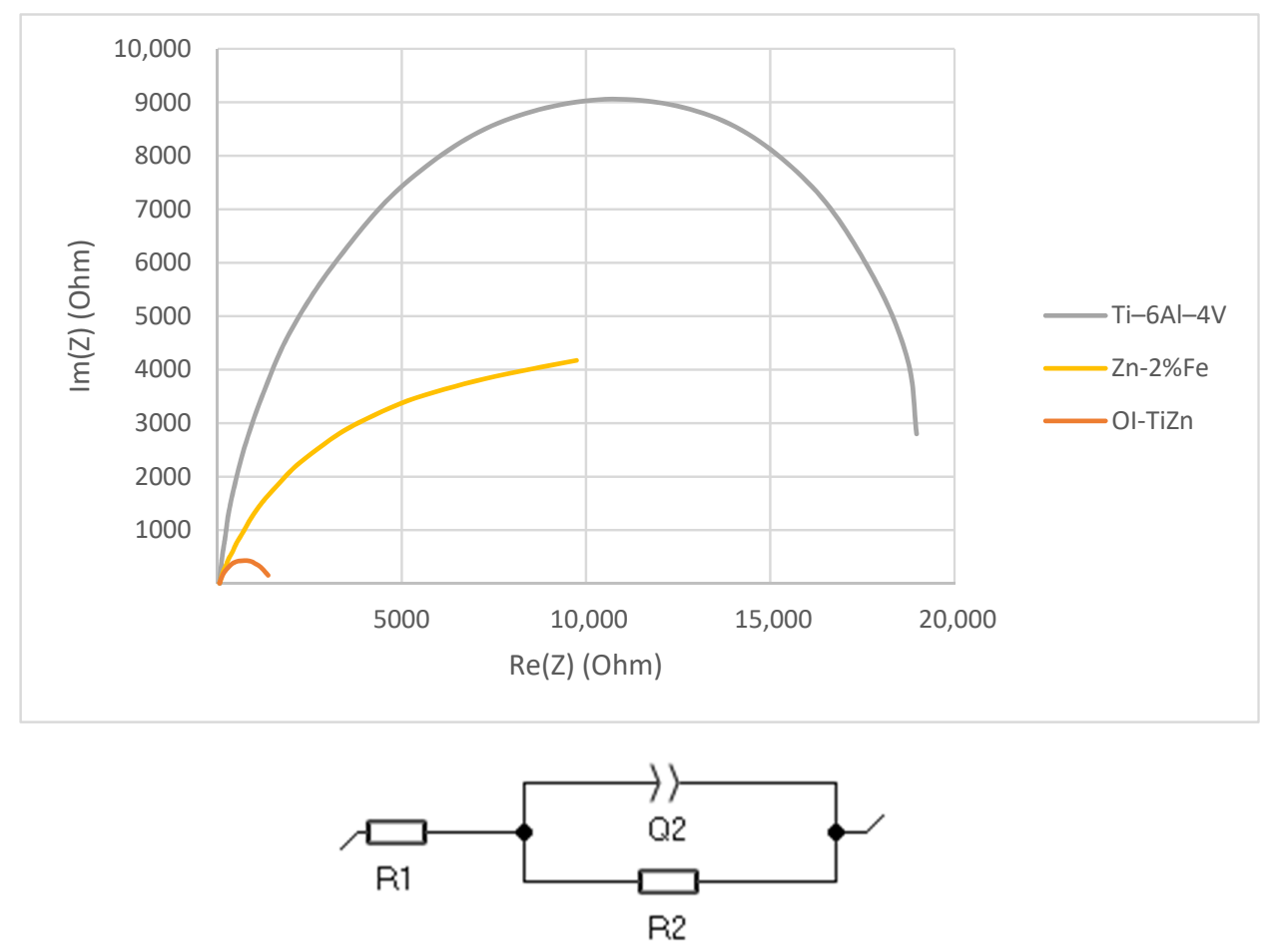

Figure 12. (a) Nyquist plots of Ti-base lattice, Zn-2\%Fe alloy, and OI-TiZn system; (b) fitted electrical equivalent circuit (EEC).

Table 3. The electrical equivalent circuit parameters fitted from the Nyquist plots.

\begin{tabular}{cccc}
\hline & Ti-6Al-4V & Zn-2\%Fe & OI-TiZn \\
\hline R1 $(\Omega)$ & $48.2 \pm 2.7$ & $49.0 \pm 1.0$ & $75.9 \pm 24.1$ \\
R2 $(\Omega)$ & $21,106 \pm 4276$ & $10,031 \pm 1963$ & $1182 \pm 167$ \\
Q2 $(\mu \mathrm{F})$ & $47 \pm 4$ & $137 \pm 65$ & $85 \pm 7$ \\
\hline
\end{tabular}

\subsection{Cytotoxicity Analysis}

An indirect cytotoxicity analysis of the OI-TiZn system and the Ti-6Al-4V reference alloy that has excellent biocompatible properties [44] was carried out following incubation periods of $24 \mathrm{~h}$ and $48 \mathrm{~h}$, as shown in Figure 13, in terms of cell viability. In the case of the OI-TiZn system, the dilution rate was $10 \%$ in order to rectify the natural buffering gap that exists between the in vivo and in vitro conditions $[38,45]$. The obtained results clearly indicate that both the Ti-6Al-4V alloy and the OI-TiZn system can be considered to be non-cytotoxic substrates for $4 \mathrm{~T} 1$ cells due to a cell viability above $70 \%$. These quantitative results comply with ISO-10993-5 (tests for in-vitro cytotoxicity) [46], which indicates that a 
viability reduction of up to $30 \%$ is not considered to be cytotoxic. The general appearance of the $4 \mathrm{~T} 1$ cells after $48 \mathrm{~h}$, as shown in Figure 14, complies with the quantitative analysis. The cells incubated in extracts of 10\% OI-TiZn, Ti-6Al-4V alloy, and DMEM only, look normal and healthy.

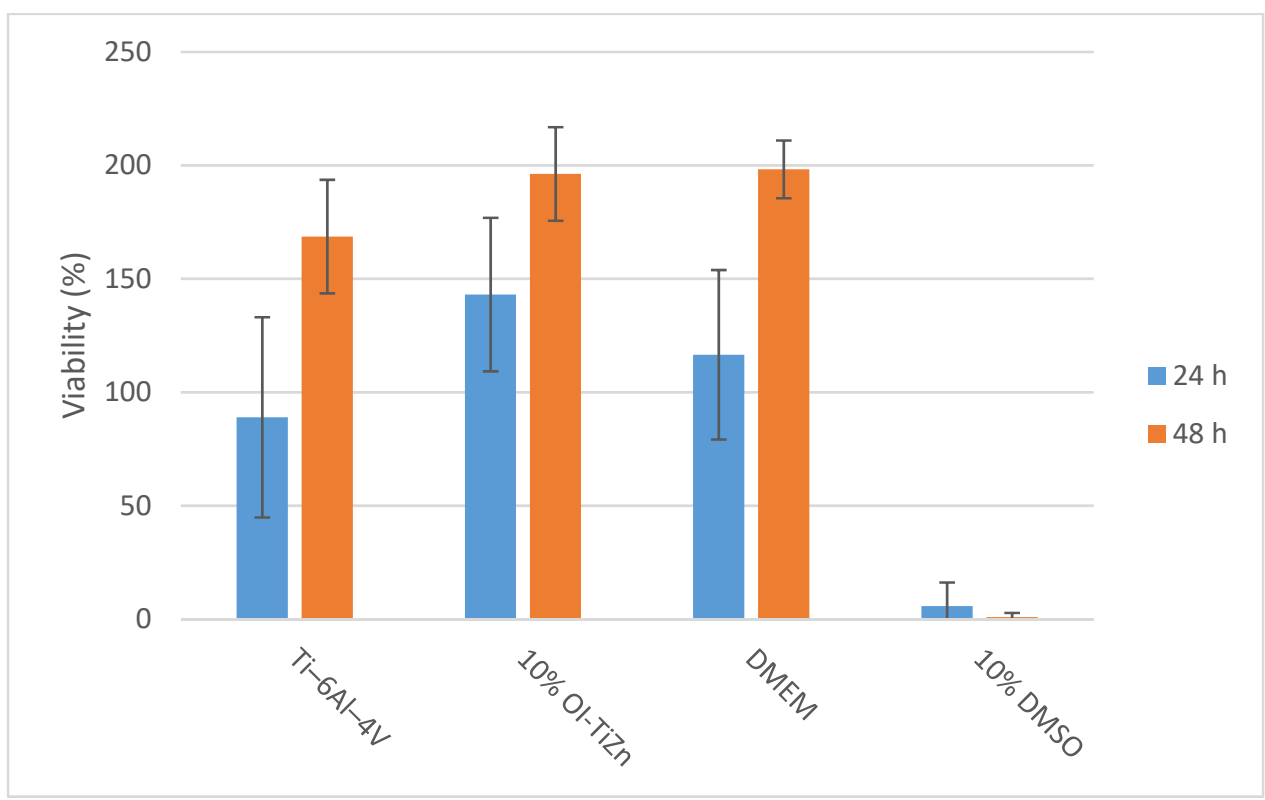

Figure 13. Viability analysis of $4 \mathrm{~T} 1$ cells in terms of their metabolic activity after incubation of $24 \mathrm{~h}$ and $48 \mathrm{~h}$ in extracts of the tested materials.
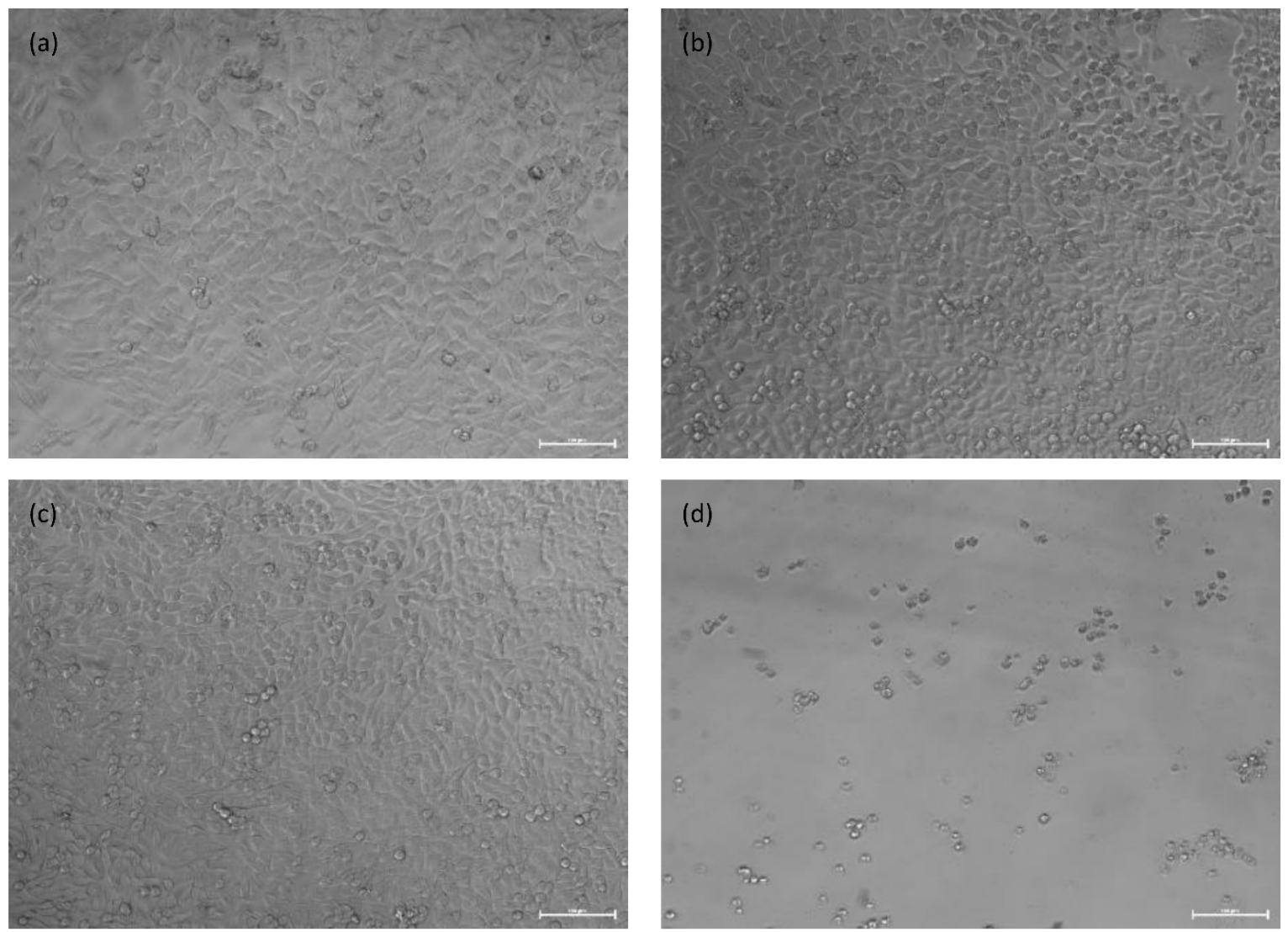

Figure 14. General appearance of $4 \mathrm{~T} 1$ cells after $48 \mathrm{~h}$ incubation in extracts of: (a) Ti-6Al-4V alloy, (b) 10\% OI-TiZn, (c) DMEM, and (d) $10 \%$ DMSO. 


\section{Discussion}

The attractiveness of an AM lattice infiltrated with a biodegradable alloy as a potential structural material for implants mainly relates to its capability to stimulate osseointegration bonding [2,3]. Furthermore, AM technologies enable the production of complex implants that can address, for example, special personal needs in dental and orthopedic operations. In the case of the OI-TiZn system, the potential osseointegration bonding can be implemented by the dissolution of the infiltrated biodegradable $\mathrm{Zn}-2 \% \mathrm{Fe}$ alloy and, in parallel, the formation of bone tissue within the open space of the permanent Ti-base lattice implant. Other inherent advantages of OI-TiZn systems relate to the capability of Zinc to stimulate bone growth [29] and to act as an antibacterial substance that can prevent infections post-implantation.

The results obtained by this study in in vitro conditions clearly demonstrate the adequate bonding created between the biodegradable $\mathrm{Zn}-2 \% \mathrm{Fe}$ alloy and the Ti-base lattice post-infiltration. This was naturally manifested by a significant increase in strength of the OI-TiZn system as compared to the monolithic lattice structure in terms of UCS- 699 vs. $430 \mathrm{MPa}$, and yield strength -606 vs. $396 \mathrm{MPa}$. In addition, the fact that the mechanical integrity of the OI-TiZn was maintained following the compression test failure can also serve as an indication of the satisfactory bonding between the degradable alloy and the Ti lattice. The adequate matching between the infiltrated $\mathrm{Zn}-2 \% \mathrm{Fe}$ alloy and the Ti-base lattice was also visible through the microstructure analysis. It is believed that the interface layer, with a width of about $130 \mu \mathrm{m}$ that includes $\mathrm{TiZn}_{3}$ precipitates, is created by mutual diffusion between the infiltrated alloy and the Ti-base lattice. Consequently, this can contribute to the improved bonding between those two materials.

The corrosion rate of the OI-TiZn system in terms of the immersion test, potentiodynamic polarization, and EIS analysis in a simulated physiological solution was basically similar and within the range of about $0.15-1.6 \mathrm{mmpy}$. Although this was relatively increased as compared to the corrosion rate of the biodegradable $\mathrm{Zn}-2 \% \mathrm{Fe}$ alloy $(0.033 \pm 0.75 \mathrm{mmpy})$ due to microgalvanic effects, this can be basically tolerated in in vivo conditions. In fact, according to Guillory et al. [33], arterial implants produced from pure Zn with corrosion rates of about $0.02-0.05 \mathrm{mmpy}$ may provoke fibrous encapsulation that can isolate the implant and arrest the biodegradation process $[47,48]$. As a result, the relatively increased corrosion rate of the OI-TiZn system can be considered to be an inherent advantage that may prevent the potential danger of encapsulation processes in in vivo conditions. Furthermore, the prospects of the OI-TiZn system as an adequate implant material were also supported by the indirect cytotoxicity evaluation analysis in terms of cell viability. This clearly indicated that the OI-TiZn system can be related as a non-cytotoxic substance to relatively sensitive $4 \mathrm{~T} 1$ cells. The average cells' viability on the OI-TiZn system after $24 \mathrm{~h}$ and $48 \mathrm{~h}$ of incubation was $140 \%$ and $190 \%$, respectively, which is well above the required cell viability of $70 \%$. In addition, it was evident that the general appearance of the cells post-incubation was quite normal and healthy.

\section{Conclusions}

The in vitro results obtained by this study clearly demonstrate the prospects of an OITiZn system as an adequate structural material for implants that can potentially improve osseointegration bonding. This was illustrated by indirect cytotoxicity analysis in terms of cell viability, which showed that an OI-TiZn system can be related as a non-cytotoxic substance to relatively sensitive 4T1 cells. Although the corrosion rate of the OI-TiZn system in a simulated physiological solution was slightly increased due to microgalvanic effects, the obtained degradation rate can be considered to be quite tolerable. The adequate bonding obtained between the Ti-base lattice and the infiltrated $\mathrm{Zn}-2 \% \mathrm{Fe}$ alloy was able to maintain the mechanical integrity of the OI-TiZn system under compression test conditions. This study should be followed by in vivo experiments that will demonstrate the capability of an OI-TiZn system to act as the structural material to enhance osseointegration. 
Author Contributions: Conceptualization and design of the experiments: E.A., A.S. and N.G.; Writing: N.G. and E.A.; performed the experiments: N.G.; assisted with the experiments: T.R.; assisted with the experiments relating to cytotoxicity evaluation: R.V. All authors have read and agreed to the published version of the manuscript.

Funding: This research received no external funding.

Institutional Review Board Statement: Not applicable.

Informed Consent Statement: Not applicable.

Data Availability Statement: Data Sharing Not Applicable.

Conflicts of Interest: The authors declare no conflict of interest.

\section{References}

1. Albrektsson, T.; Brånemark, P.-I.; Hansson, H.-A.; Lindström, J. Osseointegrated Titanium Implants: Requirements for Ensuring a Long-Lasting, Direct Bone-to-Implant Anchorage in Man. Acta Orthop. Scand. 1981, 52, 155-170. [CrossRef] [PubMed]

2. Albrektsson, T.; Chrcanovic, B.; Jacobsson, M.; Wennerberg, A. Osseointegration of Implants-A Biological and Clinical Overview. JSM Dent. Surg. 2017, 2, 1022.

3. Castellani, C.; Lindtner, R.A.; Hausbrandt, P.; Tschegg, E.; Stanzl-Tschegg, S.E.; Zanoni, G.; Beck, S.; Weinberg, A.-M. Boneimplant interface strength and osseointegration: Biodegradable magnesium alloy versus standard titanium control. Acta Biomater. 2011, 7, 432-440. [CrossRef] [PubMed]

4. Kobryn, P.A.; Semiatin, S.L. Mechanical Properties of Laser-Deposited Ti-6Al-4V. In International Solid Freeform Fabrication Symposium; Wright-Patterson Air Force Base: Ohio, OH, USA, 2001.

5. Murr, L.; Esquivel, E.; Quinones, S.; Gaytan, S.; Lopez, M.; Martinez, E.; Medina, F.; Hernandez, D.; Martinez, J.; Stafford, S.; et al. Microstructures and mechanical properties of electron beam-rapid manufactured Ti-6Al-4V biomedical prototypes compared to wrought Ti-6Al-4V. Mater. Charact. 2009, 60, 96-105. [CrossRef]

6. Sing, S.L.; An, J.; Yeong, W.Y.; Wiria, F.E. Laser and electron-beam powder-bed additive manufacturing of metallic implants: A review on processes, materials and designs. J. Orthop. Res. 2016, 34, 369-385. [CrossRef]

7. Beaman, J.; Bourell, D.L.; Seepersad, C.; Kovar, D. Additive Manufacturing Review-Early Past to Current Practice. J. Manuf. Sci. Eng. 2020, 142, 1-50. [CrossRef]

8. Mahmoud, D.; Elbestawi, M.A. Lattice Structures and Functionally Graded Materials Applications in Additive Manufacturing of Orthopedic Implants: A Review. J. Manuf. Mater. Process. 2017, 1, 13. [CrossRef]

9. Balog, M.; Snajdar, M.; Krizik, P.; Schauperl, Z.; Stanec, Z.; Catic, A. Titanium-Magnesium Composite for Dental Implants (BIACOM). In Proceedings of the International Conference on Martensitic Transformations, Chicago, IL, USA, 9-14 July 2017; pp. 271-284.

10. Jiang, G.; Wang, C.; Li, Q.; Dong, J.; He, G. Porous titanium with entangled structure filled with biodegradable magnesium for potential biomedical applications. Mater. Sci. Eng. C 2015, 47, 142-149. [CrossRef] [PubMed]

11. Bruni, S.; Martinesi, M.; Stio, M.; Treves, C.; Bacci, T.; Borgioli, F. Effects of surface treatment of Ti-6Al-4V titanium alloy on biocompatibility in cultured human umbilical vein endothelial cells. Acta Biomater. 2005, 1, 223-234. [CrossRef]

12. Niinomi, M. Mechanical properties of biomedical titanium alloys. Mater. Sci. Eng. A 1998, 243, 231-236. [CrossRef]

13. Liang, H.; Yang, Y.; Xie, D.; Li, L.; Mao, N.; Wang, C.J.; Tian, Z.; Jiang, Q.; Shen, L. Trabecular-like Ti-6Al-4V scaffolds for orthopedic: Fabrication by selective laser melting and in vitro biocompatibility. J. Mater. Sci. Technol. 2019, 35, $1284-1297$. [CrossRef]

14. Attar, H.; Ehtemam-Haghighi, S.; Soro, N.; Kent, D.; Dargusch, M.S. Additive manufacturing of low-cost porous titanium-based composites for biomedical applications: Advantages, challenges and opinion for future development. J. Alloys Compd. 2020, 827, 154263. [CrossRef]

15. Jawed, S.; Rabadia, C.D.; Liu, Y.; Wang, L.; Qin, P.; Li, Y.; Zhang, X.; Zhang, L. Strengthening mechanism and corrosion resistance of beta-type Ti-Nb-Zr-Mn alloys. Mater. Sci. Eng. C 2020, 110, 110728. [CrossRef]

16. Gudkov, S.V.; Simakin, A.V.; Sevostyanov, M.A.; Konushkin, S.V.; Losertová, M.; Ivannikov, A.Y.; Kolmakov, A.G.; Izmailov, A.Y. Manufacturing and Study of Mechanical Properties, Structure and Compatibility with Biological Objects of Plates and Wire from New Ti-25Nb-13Ta-5Zr Alloy. Metals 2020, 10, 1584. [CrossRef]

17. Liang, C.; Zhao, J.; Chang, J.; Wang, H. Microstructure evolution and nano-hardness modulation of rapidly solidified Ti-Al-Nb alloy. J. Alloys Compd. 2020, 836, 155538. [CrossRef]

18. Kafri, A.; Ovadia, S.; Goldman, J.; Drelich, J.; Aghion, E. The Suitability of Zn-1.3\%Fe Alloy as a Biodegradable Implant Material. Metals 2018, 8, 153. [CrossRef]

19. Zhao, D.; Brown, A.; Wang, T.; Yoshizawa, S.; Sfeir, C.; Heineman, W.R. In vivo quantification of hydrogen gas concentration in bone marrow surrounding magnesium fracture fixation hardware using an electrochemical hydrogen gas sensor. Acta Biomater. 2018, 73, 559-566. [CrossRef] [PubMed] 
20. Zhao, D.; Wang, T.; Kuhlmann, J.; Dong, Z.; Chen, S.; Joshi, M.; Salunke, P.; Shanov, V.N.; Hong, D.; Kumta, P.N.; et al. In vivo monitoring the biodegradation of magnesium alloys with an electrochemical $\mathrm{H}_{2}$ sensor. Acta Biomater. 2016, 36, 361-368. [CrossRef] [PubMed]

21. Aghion, E.; Gueta, Y.; Moscovitch, N.; Bronfin, B. Effect of yttrium additions on the properties of grain-refined Mg-3\%Nd alloy. J. Mater. Sci. 2008, 43, 4870-4875. [CrossRef]

22. Aghion, E.; Bronfin, B.; Eliezer, D.; Von Buch, F.; Schumann, S.; Friedrich, H.E. The Art of Developing New Magnesium Alloys for High Temperature Applications. Mater. Sci. Forum 2003, 419-422, 407-418. [CrossRef]

23. Levy, G.K.; Kafri, A.; Ventura, Y.; Leon, A.; Vago, R.; Goldman, J.; Aghion, E. Surface stabilization treatment enhances initial cell viability and adhesion for biodegradable zinc alloys. Mater. Lett. 2019, 248, 130-133. [CrossRef]

24. Kabir, H.; Munir, K.; Wen, C.; Li, Y. Recent research and progress of biodegradable zinc alloys and composites for biomedical applications: Biomechanical and biocorrosion perspectives. Bioact. Mater. 2021, 6, 836-879. [CrossRef]

25. Li, H.F.; Xie, X.H.; Zheng, Y.F.; Cong, Y.; Zhou, F.Y.; Qiu, K.J.; Wang, X.; Chen, S.H.; Huang, L.; Tian, L.; et al. Development of biodegradable Zn-1X binary alloys with nutrient alloying elements Mg, Ca and Sr. Sci. Rep. 2015, 5, srep10719. [CrossRef]

26. Sikora-Jasinska, M.; Mostaed, E.; Beanland, R.; Mantovani, D.; Vedani, M. Fabrication, mechanical properties and in vitro degradation behavior of newly developed $\mathrm{Zn} \mathrm{Ag} \mathrm{alloys} \mathrm{for} \mathrm{degradable} \mathrm{implant} \mathrm{applications.} \mathrm{Mater.} \mathrm{Sci.} \mathrm{Eng.} \mathrm{C} \mathrm{2017,} \mathrm{77,}$ 1170-1181. [CrossRef]

27. Lin, S.; Wang, Q.; Yan, X.; Ran, X.; Wang, L.; Zhou, J.G.; Hu, T.; Wang, G. Mechanical properties, degradation behaviors and biocompatibility evaluation of a biodegradable Zn-Mg-Cu alloy for cardiovascular implants. Mater. Lett. 2019, 234, $294-297$. [CrossRef]

28. Tong, X.; Zhang, D.; Zhang, X.; Su, Y.; Shi, Z.; Wang, K.; Lin, J.; Li, Y.; Lin, J.; Wen, C. Microstructure, mechanical properties, biocompatibility, and in vitro corrosion and degradation behavior of a new $\mathrm{Zn}-5 \mathrm{Ge}$ alloy for biodegradable implant materials. Acta Biomater. 2018, 82, 197-204. [CrossRef] [PubMed]

29. Ceylan, M.N.; Akdas, S.; Yazihan, N. Is Zinc an Important Trace Element on Bone-Related Diseases and Complications? A Meta-analysis and Systematic Review from Serum Level, Dietary Intake, and Supplementation Aspects. Biol. Trace Elem. Res. 2021, 199, 535-549. [CrossRef] [PubMed]

30. Rink, L.; Gabriel, P. Zinc and the immune system. Proc. Nutr. Soc. 2000, 59, 541-552. [CrossRef] [PubMed]

31. Roselli, M.; Finamore, A.; Britti, M.S.; Bosi, P.; Oswald, I.; Mengheri, E. Alternatives to in-feed antibiotics in pigs: Evaluation of probiotics, zinc or organic acids as protective agents for the intestinal mucosa. A comparison of in vitro and in vivo results. Anim. Res. 2005, 54, 203-218. [CrossRef]

32. Ibs, K.-H.; Rink, L. Zinc-Altered Immune function. J. Nutr. 2003, 133, 1452S-1456S. [CrossRef]

33. Guillory, R.J.; Bowen, P.K.; Hopkins, S.P.; Shearier, E.R.; Earley, E.J.; Gillette, A.A.; Aghion, E.; Bocks, M.L.; Drelich, J.W.; Goldman, J. Corrosion Characteristics Dictate the Long-Term Inflammatory Profile of Degradable Zinc Arterial Implants. ACS Biomater. Sci. Eng. 2016, 2, 2355-2364. [CrossRef]

34. Kafri, A.; Ovadia, S.; Yosafovich-Doitch, G.; Aghion, E. The Effects of 4\%Fe on the Performance of Pure Zinc as Biodegradable Implant Material. Ann. Biomed. Eng. 2019, 47, 1400-1408. [CrossRef]

35. Kaya, A.; Uzan, P.; Eliezer, D.; Aghion, E. Electron microscopical investigation of as cast AZ91D alloy. Mater. Sci. Technol. 2000, 16, 1001-1006. [CrossRef]

36. Jiang, G.; Li, Q.; Wang, C.; Dong, J.; He, G. Fabrication of graded porous titanium-magnesium composite for load-bearing biomedical applications. Mater. Des. 2015, 67, 354-359. [CrossRef]

37. Buchanan, R.A.; Stansbury, E.E. Electrochemical Corrosion. In Handbook of Environmental Degradation of Materials, 2nd ed.; Kutz, M., Ed.; William Andrew Publishing: Norwich, NY, USA, 2012; pp. 87-125.

38. Wang, J.; Witte, F.; Xi, T.; Zheng, Y.; Yang, K.; Yang, Y.; Zhao, D.; Meng, J.; Li, Y.; Li, W.; et al. Recommendation for modifying current cytotoxicity testing standards for biodegradable magnesium-based materials. Acta Biomater. 2015, 21, 237-249. [CrossRef] [PubMed]

39. Li, P.; Schille, C.; Schweizer, E.; Rupp, F.; Heiss, A.; Legner, C.; Klotz, U.E.; Geis-Gerstorfer, J.; Scheideler, L. Mechanical Characteristics, In Vitro Degradation, Cytotoxicity, and Antibacterial Evaluation of Zn-4.0Ag Alloy as a Biodegradable Material. Int. J. Mol. Sci. 2018, 19, 755. [CrossRef]

40. Raghavan, V. Fe-Ti-Zn (Iron-Titanium-Zinc). J. Phase Equilibria Diffus. 2008, 29, 458. [CrossRef]

41. Qian, M.; Xu, W.; Brandt, M.; Tang, H. Additive manufacturing and postprocessing of Ti-6Al-4V for superior mechanical properties. MRS Bull. 2016, 41, 775-784. [CrossRef]

42. Maskery, I.; Aboulkhair, N.T.; Aremu, A.; Tuck, C.; Ashcroft, I. Compressive failure modes and energy absorption in additively manufactured double gyroid lattices. Addit. Manuf. 2017, 16, 24-29. [CrossRef]

43. Itzhak, D.; Aghion, E. An anodic behaviour study of an analogical sintered system of austenitic stainless steel in $\mathrm{H}_{2} \mathrm{SO}_{4}$ solution. Corros. Sci. 1984, 24, 145-149. [CrossRef]

44. Dong, Y.; Tang, J.; Wang, D.; Wang, N.; He, Z.; Li, J.; Zhao, D.; Yan, M. Additive manufacturing of pure Ti with superior mechanical performance, low cost, and biocompatibility for potential replacement of Ti-6Al-4V. Mater. Des. 2020, 196, 109142. [CrossRef]

45. Hong, D.; Saha, P.; Chou, D.-T.; Lee, B.; Collins, B.E.; Tan, Z.; Dong, Z.; Kumta, P.N. In vitro degradation and cytotoxicity response of $\mathrm{Mg}-4 \% \mathrm{Zn}-0.5 \% \mathrm{Zr}$ (ZK40) alloy as a potential biodegradable material. Acta Biomater. 2013, 9, 8534-8547. [CrossRef] [PubMed] 
46. ISO. ISO-10993-5 Biological Evaluation of Medical Devices, Part 5: Tests for In Vitro Cytotoxicity; ISO Central Secretaria: Geneva, Switzerland, 2009.

47. Tjellström, A.; Rosenhall, U.; Lindström, J.; Hallén, O.; Albrektsson, T.; Brånemark, P.I. Five-Year Experience with Skin-Penetrating Bone-Anchored Implants in the Temporal Bone. Acta Oto-Laryngol. 1983, 95, 568-575. [CrossRef] [PubMed]

48. Geetha, M.; Singh, A.K.; Asokamani, R.; Gogia, A.K. Ti based biomaterials, the ultimate choice for orthopaedic implants-A review. Prog. Mater. Sci. 2009, 54, 397-425. [CrossRef] 